\title{
Greetings From the Editor of Clinical Thyroidology
}

\section{DEAR COLLEAGUES,}

A warm holiday greeting to all. We are delighted to bring you our commentaries of a top 10 selection of articles from the clinical thyroid literature to finish off 2019. In this issue, Dr. Charles Emerson examines two related articles regarding the shared patient-physician decisions important in the treatment of hypothyroidism. On the same topic, Dr. Trevor Angell then reviews a study analyzing the issues involved in the treatment of subclinical hypothyroidism among a cohort of individuals 80 years of age or older. Turning to the topic of hyperthyroidism, Dr. Brian Kim examines a study analyzing the relationship between correction of hyperthyroidism and weight gain, while Dr. David Cooper reviews a Japanese study on the associations between antithyroid drug use and liver injury in a cohort of over 18,000 patients.

In the area of thyroid nodules and thyroid cancer, Dr. Stephanie Fish reviews a recent meta-analysis of the available data surrounding the various ultrasound risk-stratification systems commonly used, including those by AACE, ACE, AME, and ATA and ACR-TIRADS, EU-TIRADS, and K-TIRADS. The important consideration of frailty as a risk factor in patients undergoing thyroid and parathyroid surgeries is reviewed by Dr. Lisa Orloff. Drs. Masha Livhits and Michael Yeh then discuss an important clinical concern: What are the mortality risks of the various aggressive variants of papillary thyroid cancer? In her review, Dr. Sun Lee discusses the findings of a study assessing the pregnancy-related concerns of radioactive iodine use in patients with differentiated thyroid cancer, an oft-debated topic. From his perspective as a medical oncologist and as part of our continuing series jointly between the American Thyroid Association (ATA) and the International Thyroid Oncology Group (ITOG), Dr. Jochen Lorch shares a review of a recent study examining the role of pembrolizumab plus chemoradiation in anaplastic thyroid cancers. Finally, in an interesting commentary relevant to current health care discussions, Dr. Douglas Van Nostrand shares his perspective on how insurance coverage plans impact thyroid cancer care in the United States.

Finally, we are thrilled when we are able to connect with so many new global friends and readers through our social media channels. Come join the conversation!

Twitter: $\quad$ https://twitter.com/clinicalthyroid (@clinicalthyroid)

Facebook: https://www.facebook.com/ ThyroidAssociation

LinkedIn: https://www.linkedin.com/company/ american-thyroid-association

Youtube: https://www.youtube.com/user/ thyroidorg

Please kindly keep in mind that the reviews covered in Clinical Thyroidology are also translated into shorter lay summaries in our sister journal, Clinical Thyroidology for the Public, that is edited by Dr. Alan Farwell and his team each month. These more concise summaries may be helpful to patients who ask about a specific recent article in the published literature. 


\section{Greetings From the Editor of Clinical Thyroidology}

Thank you for your continued support, readership, and interest in the journal. We will continue to bring you clear and concise summaries each month of the most impactful papers published in the current clinical thyroid literature. Please feel free to send me any questions or comments at clinicalthyroidology@ thyroid.org.
I hope that everyone has a healthy, safe, and wonderful holiday season. See you in 2020.

Warm regards,

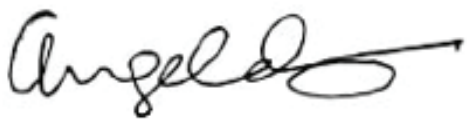

Angela M. Leung, MD, MSc

Editor-in-Chief, Clinical Thyroidology

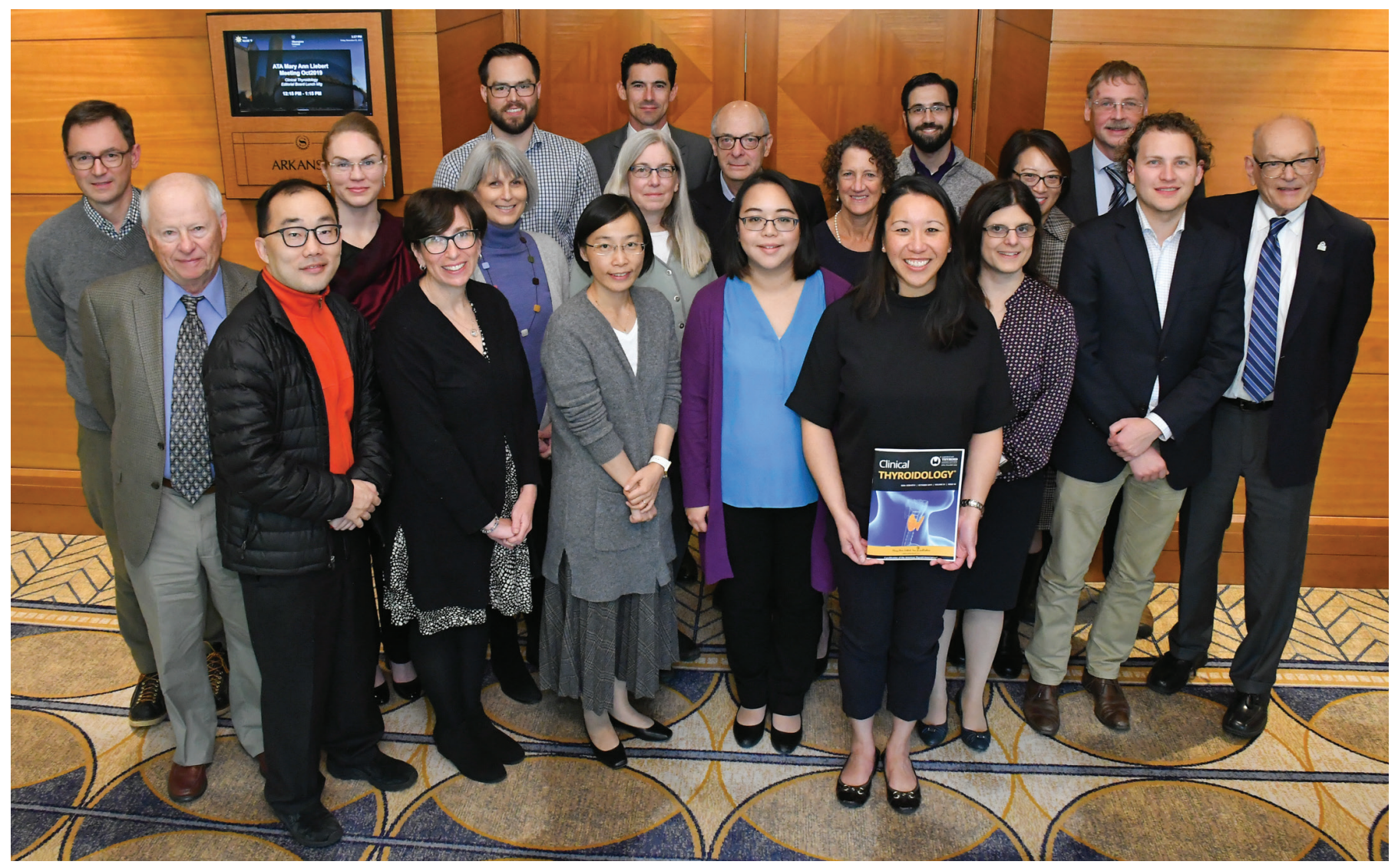

Clinical Thyroidology Editorial Meeting (ATA Annual Meeting, Chicago), November 1, 2019. Pictured (left to right): First Row: Brian W. Kim, Stephanie Fish, Haixia Guan, Sun Y. Lee, Angela M. Leung, Maria Papaleontiou, Second Row: Charles H. Emerson, Sophie Mohin Reisz, Catherine A. Dinauer, Mary H. Samuels, David S. Cooper, Lisa A. Orloff, Tracy S. Wang, Tim I.M. Korevaar, Jerome Hershman, Third Row: Daniel J. Toft, Tyler Drake, Trevor E. Angell, Benjamin Gigliotti, Martin Biermann, Not Pictured: Masha J. Livhits, Jochen H. Lorch, Elizabeth N. Pearce, Marius N. Stan, Douglas Van Nostrand, Michael W. Yeh. 